\title{
Under-nutrition in India - A Forgotten National Nutrition Policy without a National Programme
}

\author{
VEENA S RAO* \\ Advisor, Karnataka Nutrition Mission, State Institute of Health and Family Welfare Building, Room No. \\ $4 \& 5,1^{\text {st }}$ Cross, Magadi Road, Bangalore 560 023, India
}

(Received on 13 May 2016; Accepted on 10 June 2016)

\begin{abstract}
This Paper analyses why and for how long high levels of malnutrition have afflicted India's population. It does a historical analysis of how two centuries of colonial rule created the enabling environment for perpetuation of chronic malnutrition through interplay of increasing poverty, decreasing literacy, de-industrialization, an increased agricultural labour force, low wages, deteriorating health and nutritional status. The paper discusses the James Bhore Committee Report, 1946, first Health and Nutrition Survey in India, and the alarming nutrition data it reveals. It examines independent India's responses - Article 47 of the Constitution, the beginnings of nutrition governance in India, development of nutrition strategies and interventions in the Five Year Plans, the announcement of the Minimum Needs Programme in 1974, launch of the ICDS in 1975, and adoption of the National Nutrition Policy (NNP) in 1993, and evaluates their impact. The paper concludes that the problem of under-nutrition in India could decrease faster if its structural causes are programmatically addressed, namely, protein-calorie-micronutrient deficit in about $50 \%$ of the people's diet; its inter-generational character; the information and awareness deficit in the community about proper nutritional care of infants, children, adolescent girls, and pregnant women. Important prescriptions of the National Nutrition Policy, 1993, were never implemented, and India has no national programme to eradicate malnutrition. The paper concludes with recommendations that the Niti Aayog take charge of this multi-sectoral subject, and constitute a High Power Committee to revise the NNP and draft the National Nutrition Mission within a given time frame.
\end{abstract}

Keywords: Bhore Committee Report; Inter-generational Malnutrition; Five Year Plans; National Nutrition Policy; Niti Aayog

\section{Under-nutrition in India - A forgotten National Nutrition Policy without a National Programme \\ Looking Back - For how long have high levels of malnutrition afflicted India's population?}

Let me begin this paper by quoting from the conclusion of the opening chapter of one of the most important and pioneering reports related to the problem of undernutrition in India.

"To sum up, the factors responsible for the low level of ill-health in India include, among others, the prevalence of malnutrition and undernutrition among appreciable sections of the people, the serious inadequacy of existing provision for affording health protection to the community and a group of social causes consisting of poverty and unemployment, illiteracy and ignorance of the hygienic mode of life and certain customs such as early marriage. The cumulative effect of these factors is seen in the incidence of a large amount of preventable morbidity and mortality in the community. The continued prevalence of such conditions for many generations has probably helped to create in the minds of the people an attitude of passive acceptance of the existing state of affairs. This attitude will have to be overcome and their active cooperation enlisted in the campaign against disease, insanitation and undesirable personal and community habits, if any lasting improvement in the public health is to be achieved."

This is not a Report of recent years, however 
relevant and contemporary it might sound. This is the concluding paragraph of Chapter 1 of 'A brief Survey of the State of the Public Health' - India's first comprehensive report on nutrition and health - the 'Report of the Health Survey and Development Committee', 1946, headed by Sir Joseph Bhore. Apart from stating the universally known connectivity between health and nutrition, this Report vigorously emphasizes the importance of proper sanitation, (something omitted even in the National Nutrition Policy, 1993) for improving nutritional status, and provides valuable insights regarding behavioural and social practices that negatively impact nutritional status.

The author is particularly impressed by the Report's comments that, "The continued prevalence of such conditions for many generations has probably helped to create in the minds of the people an attitude of passive acceptance of the existing state of affairs. This attitude will have to be overcome and their active cooperation enlisted in the campaign against disease, insanitation and undesirable personal and community habits, if any lasting improvement in the public health is to be achieved." These factors continue to persist in India even today, particularly the attitude of passive acceptance of an affliction, which they do not understand why they have.

It is also important to revisit the findings of the food surveys conducted between the years 1935 to 1948. These are adequately quoted and form the basis of the recommendations of the First Five Year Plan, (1951-1956), regarding nutrition in Chapter 32, Paras 25 and 26.

Para 25 reads as: "The average diet of an Indian is lopsided primarily because of its extremely high cereal content. The other noticeable feature is that the diet lacks in adequate amounts of protective foods leading to inadequacy and very often to total lack of proteins of good quality. Inadequacy of minerals and most of the important vitamins in more or less varying degrees is the other important feature. It has not been sufficiently realized that the inadequacy of B group of vitamins is of the most serious import in view of the large intake of carbohydrates. Intake of vitamins $\mathrm{A}$ and $\mathrm{C}$ also is often inadequate". These surveys have led to the following observations: "It appears that two-thirds of the families did not consume any fruits and nuts at all. About one-third of the families did not consume sugar and jaggery, meat, fish or flesh foods, and a quarter of the family groups did not consume milk and milk products or leafy vegetables. Again, amongst the groups of families consuming particular foodstuffs the intake of leafy vegetables, other vegetables, ghee and vegetable oil and pulses was below the desired or recommended level. Only in about one-fifth of the groups of families surveyed was the intake of pulses and other vegetables up to the recommended level. Though any generalisation on the data presented is not desirable for reasons more than one, yet it may be stated that in about four-fifths of the families surveyed the intake of protective foods was either nil or below standard.

Para 26. "The bulk of the population cannot afford to purchase a satisfactory diet. In terms of average income it would hardly be possible for more than 30 per cent of the population to feed themselves on an adequate scale" (First Five Year Plan, Chapter 32, 1951-56).

\section{Colonialism, the enabling environment for India's chronic malnutrition and micronutrient deficiency}

The reports referred to above should remind us that under-nutrition and micronutrient deficiency which even today afflict more than $50 \%$ of our population, is not something that was suddenly acquired because of successive natural calamities, food shortages or war. Clearly, it is one of the outcomes of sustained socio-economic deterioration caused by the increasing poverty in the $19^{\text {th }}$ and $20^{\text {th }}$ centuries under colonial rule, brought about by changed occupations and agricultural patterns enforced by the colonial masters (P. Ponram, 2014) and surging illiteracy resulting from depriving the existing and flourishing indigenous system of education of patronage and funds (Dharampal, 1985). Reduced incomes, poverty, compounded by rapidly growing illiteracy, poor health care, and lack of opportunity for upward economic or social mobility, created the most enabling environment for chronic malnutrition and micronutrient deficiency among the general population of India, the remnants of which persist even today.

The conscious policy of the colonial government to de-industrialize India, and gradually wipe out any industry that manufactured finished products, drove 
the unemployed artisan and weaver sector into agriculture. Simultaneously, there was also a conscious policy of converting more and more agricultural lands for growing cash crops. Starting from 1850, over 500,00 acres of the most fertile Ganges basin traditionally growing agricultural crops were converted into poppy farms by 1900 , for opium trade with China (P. Ponram, 2014).

By the early twentieth century, three out of four Indians were employed in agriculture, famines were common, and food consumption per capita declined in every decade (ibid). Colonialism reversed India into an agricultural economy with illiterate unskilled labour and low productivity, and scarcity of skills, capital and knowledge. The intensity of poverty and malnutrition kept increasing during the colonial period, the results of which are documented in the Bhore Committee Report and the food surveys, 1935 to 1948, cited above.

Independent India was born with a population having the following human development indicators a per capita income of a meagre Rs 249.6, a literacy rate of $18.33 \%$ (with female literacy at $8.86 \%$ ) (data from National Commission on Population), male and female life expectancy at 26.91 and 26.56 years respectively, a death rate of 22.8 per 1000 , infant mortality rate of 158 per 1000 , and maternal mortality at 20 per 1000 live births, with only one third of the population having the income to feed themselves adequately (First Five Year Plan, 1951-56).

\section{Independent India's Response and the Beginnings of a Nutrition Policy}

From the above Reports, it is clear that the population of independent India suffered from high rates of undernutrition and severe micronutrient deficiencies. The first State response is articulated in the highest law of the land, the Constitution of India, in Article 47 of the Directive Principles of State Policy:

"Duty of the State to raise the level of nutrition and the standard of living and to improve public health.-

The State shall regard the raising of the level of nutrition and the standard of living of its people and the improvement of public health as among its primary duties and, in particular, the State shall endeavour to bring about prohibition of the consumption except for medicinal purposes of intoxicating drinks and of drugs which are injurious to health."

\section{The Five Year Plans and the National Nutrition Policy, 1993}

The National Nutrition Policy (NNP) 1993 is India's primary national policy directly governing the subject of under-nutrition and micronutrient deficiency. It was followed up by the National Plan of Action on Nutrition 1995.

Prior to the NNP, the development of India's policy regarding nutrition can be gleaned from the Five Year Plans.

The Nutrition Section of the First Five Year Plan (1951-56) starts with the economic dimension of nutrition - 'Nutrition is perhaps the most important single factor in the maintenance of health and resistance to disease. The state of nutrition has a direct bearing on the productive capacity of an individual. Several studies carried out in different parts of the world give a direct correlation between calorie consumption and accomplishment of workers. There is reason to believe that both under-nutrition and malnutrition exist widely in the country.'

This simple but fundamental economic correlation between the state of nutrition and economic productivity, though highlighted in our very First Five Year Plan, has not yet been grasped in our economic aspirations towards faster growth and higher Gross Domestic Product (GDP).

The First Plan focused on setting up the basic health infrastructure for the country and addressing the more visible, clinical manifestation of malnutrition and micronutrient deficiencies, such as, nutritional blindness, beri beri, pellagra, marasmus and kwashiorkor.

The Second Five Year Plan (1956-61) while primarily addressing food production and food security, entrusted the calculation of nutrition data to the Indian Council of Medical Research (ICMR). Food technology for improving nutritive value of foods and production of fruits and vegetables was also emphasized. Priority was placed for improving nutrition of vulnerable groups, such as expectant and nursing mothers, infants, pre-school and school going children as its specific objective. It recommended that, 'To the extent milk powder and food supplements like cod liver oil and vitamins are available for distribution, this consideration should be specially kept in view. 
Efforts to provide mid-day meals for school-going children should also be made.'

The Third Five Year Plan (1961-66) admits that 'During the first two Plans there has been no concerted effort to improve nutrition, change food habits or create great awareness of the problem. With the increase in production and improvement in economic conditions envisaged for the Third Plan, a systematic approach to the problem of nutrition should now be feasible.' (Para 55 of Chapter 32 on Health and Family Planning) In Para 56, it states that 'At the present stage of development the programme for improving nutrition falls broadly under two heads, namely, education of the public and of various groups of workers in nutrition, and measures to meet the nutritional requirements of vulnerable groups within the community.' However, no specific interventions have been recommended in the Plan.

The Fourth Five Year Plan (1969-74) saw Food and Nutrition as a separate Chapter, and spelt out an integrated approach to improve nutrition, that development in 'agriculture, along with animal husbandry and fisheries, must be regarded as the base of all effort in nutrition.'

The Mobile Food and Nutrition Extension Service and Applied Nutrition Programme for improving consumption by promoting production of fruits and vegetables, milk and fish etc, at household and community levels were important nutrition interventions during this period. The Plan contained several significant interventions to combat proteincalorie-micronutrient under-nutrition among the vulnerable groups, such as production of Balahar, low cost protein foods and weaning foods, fortification of wheat and bread, mid day meals for school going children, addressing nutritional anaemia among mothers and children, and blindness due to Vitamin A deficiency in children. The Crash Feeding Programme for pre-school children in rural, urban and tribal areas, the Balwadi Nutrition Programme for bridging the calorie and protein gap, the National Prophylaxis Programmes for Nutritional Anaemia and Nutritional Blindness due to Vitamin A deficiency, were launched in the Social Welfare and Health sectors of the Government.

However, the critical interventions for "education of the public and of various groups of workers in nutrition,' for creating nutritional awareness and behavioural change were never initiated, even though they had been repeatedly recommended from the Bhore Committee Report, 1946, and the First Plan onwards. They have continued to elude a strategy and programme during the last six decades and more. The fact that the percentage of population suffering from malnutrition far exceeds the percentage of people below the poverty line clearly establishes that under-nutrition is not merely confined to people living below the poverty line, but also extends to those with purchasing power, because of lack of information and awareness regarding proper nutritional practice and a balanced diet.

The Fifth Five Year Plan (1974-79). The concept of an integrated approach for addressing undernutrition among children and women was conceptualized in the 5th Five Year Plan (1974-79), and in 1975 the Integrated Child Development Services (ICDS) was launched in 33 Blocks. The Minimum Needs Programme (MNP) announced in 1974 was considered the core of the social sector development plan with 8 basic minimum services. These were Elementary Education, Rural Health, Rural Water Supply, Rural Electrification, Rural Roads, Rural Housing, Environmental Improvement of Urban Slums and Nutrition.

The author believes that the ICDS became the watershed moment of India's future policy towards nutrition. On the one hand, it was a step in the right direction for an integrated child development programme with the five components of supplementary nutrition, immunization, health checkup, referral services, pre-school non-formal education and nutrition and health education. On the other hand, because its objectives did contain among others, 'improvement of the nutritional and health status of children in the age-group 0-6 years,' and 'reduction of mortality, morbidity, malnutrition and school dropout', the ICDS acquired a mistaken identity of a programme to address the general subject of malnutrition in India afflicting all age groups and both sexes among the population, particularly adolescent girls and boys.

I reproduce below, some extracts from the references made in the Minimum Needs Programme about Nutrition in the Sixth Five Year Plan: 


\section{Nutrition}

14.27 "The nutrition programme has two components-(a) Special Nutrition and (b) Mid-Day Meals.

The Special Nutrition Programme (SNP) was introduced on the Non-Plan side during 1970-71 and subsequently was brought into the Fifth Plan as a part of the Minimum Needs Programme. It provides 300 calories and 8-12 grams of protein for the age group 0-6 for 300 days, and 500 calories and 25 grams of protein for the pregnant and nursing mothers for 300 days. The eligible target group for this programme as on 1-4-1980 is 70 million children of 0-6 years and 7 million mothers.

The Mid-day Meals (MDM) Programme for the age group 6-11 was introduced in 1962-63. It provides for mid-day meals to these children for 200 days in a year and 300 calories and 8-12 grams of protein per child per day. It was made a part of the Minimum Needs Programme in the Fifth Plan. It will continue as part of the MNP in the Sixth Plan."

The Planning Commission was clear in its verdict on Nutrition. India's problem of under-nutrition and micronutrient deficiencies did not require a national programme like other MNP components, such as, Elementary Education, Rural Health, Rural Water Supply etc. The ICDS and the School Mid-day meals programme would suffice to address nutrition problems afflicting the population.

The result of this has been that all Plans subsequent to the Fifth Five Year Plan have treated ICDS, originally meant to be an integrated child development programme, targeting children below six years and pregnant and nursing mothers, as a programme to combat undernutrition in India. A flawed belief also set in the minds of policy makers and planners that the problem of under-nutrition had been sufficiently addressed by the ICDS and midday meal programme, and no further initiatives were required. This flawed belief has persisted. From the Sixth Plan onwards, the concept of nutrition continued to be viewed as synonymous with the supplementary feeding component of the two national programmes, viz., the nutrition component of the ICDS for children from 0-6 years and pregnant and nursing mothers, and the Mid Day Meal Programme of the Department of Education.
The Chapter on Food and Nutrition Security in the Tenth Five Year Plan (2002-07) did contain a list of several aspirational initiatives, which included the prescriptions of previous plans, and also provided a general assessment of the nutritional status of India's population in a multi-dimensional and inter-sectoral manner. However, while stating the Goals set for the Tenth Plan in Para 3.3.155, the focus remained on under-nutrition of children below six years, reduction of Anaemia and Iodine Deficiency Disorder (IDD) and elimination of Vitamin A deficiency, all of which were covered by on-going programmes. The Tenth Plan period saw no new programmes or initiatives to address under-nutrition or follow up on any of the aspirations articulated in the Food and Nutrition Security chapter. This situation has continued till date, with a few ad hoc additions to the ICDS, such as Sabla, a scheme for Adolescent Girls announced in 2011, and the Multi Sectoral Programme to address Maternal and Child Malnutrition, being implemented in 200 high burden Districts, without any additional implementation support to the Anganwadi.

\section{A Critical Assessment}

A critical assessment of the manner in which the subject of Nutrition has been addressed in the Five Year Plans would lead one to believe that the planners were on the right track until the Fifth Five Year Plan. The ICDS was indeed a step in the right direction for Early Childhood Development, constituting an element of supplementary nutrition for children under 6 years and pregnant and lactating mothers. But, to consider the ICDS as a national programme to combat malnutrition was a step in the wrong direction.

The ICDS did not have a component of disseminating nutritional awareness to the general population that has been abundantly emphasised in all previous plans and the Bhore Committee Report. It did not address the adolescent girl's nutritional status, the critical link to ensuring the nutritional and health status of the next generation, nor did it have the capacity or wherewithal to engineer the essential convergence of critical indirect interventions, most importantly, safe drinking water and sanitation, agriculture, horticulture, fisheries etc. The ICDS could reach out only to pregnant and nursing mothers and children below 6 years, and could not touch the population dimension of India's under-nutrition, such 
as the protein calorie micronutrient deficit and Chronic Energy Deficiency among adults and adolescent girls and boys, amply brought out in the National Nutrition Monitoring Bureau (NNMB) Repeat Surveys [(NNMB Reports of the First, Second and Third surveys; (1988-99), (1988-99), (2011-12)].

The unfortunate result of this was that the larger population dimension of malnutrition, well articulated in the previous plans, got pushed outside the nutrition agenda, and is presently without any parent ministry to programme for it. So too, the Communication and Advocacy component highlighted from the time of the Bhore Committee Report, 1946, was pushed into the background. Both these issues remain undiscussed and un-addressed even today, and the absence of interventions to address them is one of the major reasons for the extremely tardy reduction of under-nutrition in India.

Malnutrition has also become a misunderstood word amongst our Planners. Often, it is considered synonymous with food programmes or with hunger or food security. Its vast inter-sectoral dimensions, inter-generational character, its relationship with poverty and income generation, its economic losses to the nation, have yet not registered in the processes of economic planning. Malnutrition is still not stated as a major national challenge by the political leadership, either at the National or State levels, and even when it is, it is never prioritized high enough to be followed up by a meaningful or effective strategy to combat it with requisite programme backup or resource allocation.

There was some hope that there would be a reorientation towards the issue of malnutrition after the Finance Minister's Budget Speech of 2012, (Para 92) that "following the decision taken by the prime minister's National Council for India's Nutritional Challenges, a multi-sectoral programme to address maternal and child malnutrition in a selected 200 high burden districts is being rolled out during 2012-13. It will harness synergies across nutrition, sanitation, drinking water, primary healthcare, women's education, food security, and consumer protection schemes" (Budget Speech, 2012-13). However, no new programme emerged from this Budget declaration.

The author believes that the Fifth Five Year Plan (1974-79) was the defining moment when Nutrition missed out on the opportunity of becoming a standalone national programme, when all other MNP issues became so. One can only assume that neither the lobby of professional nutritionists, nor the development administrators were able to impress the highest political leadership or the planners and policy makers of its long or short-term consequences on national development.

\section{The National Nutrition Policy, 1993}

A Task Force on Nutrition Policies and Programmes was set up by the Planning Commission in 1980 to work on inclusion of a nutrition component in sectoral policies and programmes. The Task Force realized the need for a Nutrition Policy for the country, and the Department of Women and Child Development, created in 1985, constituted an Expert Working Group in 1990 for formulating a Policy. The International Conference on Nutrition (ICN) jointly organised by the Food and Agriculture Organisation and World Health Organisation in December 1992 at Rome also directed all member countries to adopt a National Nutrition Policy and develop a National Plan of Action on Nutrition.

The National Nutrition Policy was adopted by the Government of India under the aegis of Department of Women and Child Development in 1993 and laid in both the Houses of Parliament. The National Nutrition Council was set up in the Planning Commission in 1994 under the Chairmanship of Hon'ble Prime Minister.

The NNP advocates a comprehensive, integrated and inter-sectoral strategy for addressing the multi faceted challenge of malnutrition, which also includes the prescription of the previous Five Year Plans.

The Policy prescribes the following Direct and Indirect interventions:

\section{Direct Interventions}

- Expanding safety nets for children

- Triggering behavioral changes among mothers

- Reaching the adolescent girls

- Ensuring better coverage of pregnant mothers so as to prevent low birth weight 
- Fortification of essential foods with appropriate nutrients

- Popularization of low cost nutritious foods

- Control of micronutrient deficiencies among vulnerable groups

\section{Indirect Interventions}

- Food security

- Improvement of dietary pattern

- Poverty alleviation programmes and strengthening of Public Distribution System

- Land reforms

- Nutrition surveillance

- Monitoring and research

- Equal remuneration

- Communication

- Minimum wage administration

- Community participation

- Education and literacy

- Improved status of women

The National Nutrition Policy 1993, even today, is one of our soundest policy documents, though it does require some updating after 23 years. Its principles are grounded in the inter-sectoral, intergenerational approach and remain as valid today as they were in 1993. Certainly, a great deal of new data and evidence regarding under-nutrition and micronutrient deficiency has emerged since 1993, and many new policies and development programmes that impact the nutrition environment have been announced since 1993, for example, the National Health Policy 2002 and the National Policy for the Empowerment of Women, 2001, (both currently under review). These policies have defined the life-cycle covering the girl child, adolescent girl and the adult woman; stated that nutrition is a continuum covering the life-cycle, and should not be compartmentalized; and emphasized essential inter-sectoral complementarities between health, nutrition, sanitation, drinking water, education, women's empowerment, and agriculture.

Volumes of nutrition data have poured in from the National Family Health Surveys, 1992-93, 19981999, 2005-06, and the NNMB Repeat Surveys, 1988-
90, 1996-97, 2011-12, and the National Sample Survey Organisation (NSSO) $68^{\text {th }}$ Round, which give us the progressive nutritional and consumption profile of our people. New research findings have been published establishing the correlation between open defecation and stunting (Spears D, 2013). The NNP must be revised to include this new data and the critical importance of safe drinking water and sanitation for improving nutritional status, presently absent in it.

While several prescriptions of the National Nutrition Policy were existing as National Programmes, such as, Vitamin A Programme, and the Anaemia Prophylaxis Programme, the ICDS, some other prescriptions which would have had immediate and far reaching positive impact on improving nutritional status of our population were ignored, such as "Fortification of Essential Foods" and "Popularization of Low Cost Nutritious Foods"; bringing about behavioural change through "Basic Health and Nutrition Knowledge" and "Communication"; and "Improvement of Dietary pattern through Production and Demonstration."

These omissions have cost the nation dearly in combating malnutrition among those under-nourished sections of the general population not covered by the ICDS or the midday meal programme, both in terms of lost time and wasted generations. This point becomes even more significant, given the fact that even though the per capita income has more than quadrupled in the last decade, and the ICDS, MDM, and the Public Distribution System have been in operation for decades, all NNMB Reports, the last being NNMB Technical Report No. 26, 2012, continuously show a large dietary deficit in terms of protein, calorie and micronutrients among more than $50 \%$ of our population of both sexes and all age groups (NNMB $3^{\text {rd }}$ Repeat Survey, 2011-12). And despite the ICDS having been in operation for the last four decades, early data emerging from the NFHS- 4 Factsheets (2015-16) covering 17 States (Fig. 1), informs us that the percentage of children from 6-23 months receiving an adequate diet ranges from a meagre $5.9 \%$ to $31.1 \%$. Clearly, there is higher correlation of dietary deficit with an awareness/ information deficit and with absence of appropriate, affordable complementary foods in the market, than there is with poverty or lack of purchasing power. And this in spite of the fact that recommendations for 
nutrition education, and popularizing of low cost foods have existed in our Plans and in the National Nutrition Policy, 1993.

In retrospect, the National Nutrition Policy, 1993, though still alive on our policy books, can unfortunately only be viewed as a forgotten or inert policy. Its implementation was to be done by an Inter-ministerial Coordination Committee in the Department of Women and Child Development, overseen by the National Nutrition Council headed by the Prime Minister. The National Nutrition Council never met and the Interministerial Coordination Committee turned out to be non-functional. No sectoral programmes were drawn up in accordance with the NNP, and consequently no budgets were allocated. The National Nutrition Policy, though a most holistic and comprehensive document, failed to get implemented into programmes, and an opportunity to highlight malnutrition as a priority and gap area in India's development agenda was missed.

However, the NNP, though it requires some updating in the light of new research, data and evidence, fundamentally remains relevant even today, even though it has been rendered inert without a national programme or political will to back it.

\section{Why Are Our Nutritional Indicators Not Improving Faster?}

This question can be answered very simply - because the primary causes of under-nutrition and micronutrient deficiency in India have not yet been addressed. Enough research has been generated in India, post independence that informs us that:

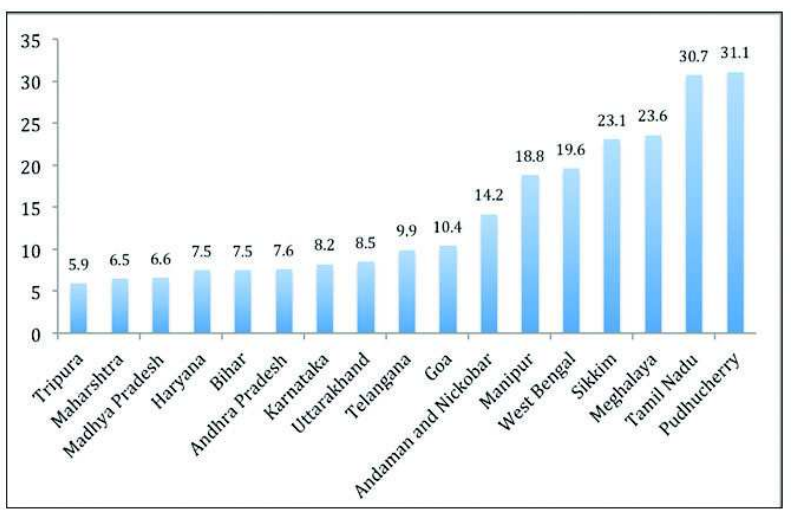

Fig. 1: Percentage of children aged 6-23 months receiving adequate diet (Source: NHFS-4 (2015-16: Factsheets)
- At least $50 \%$ of our population suffers from chronic protein calorie micronutrient deficiency (ibid). This factor has never been acknowledged by our policy makers or programme managers for finding solutions, nor taken into account for policy making or structuring strategies to address this deficit.

- Malnutrition in India is deeply rooted in the intergenerational cycle. However, the current policies and programmes do not address the issue intergenerationally by addressing the nutritional needs of the girl child, the adolescent girl and the expectant mother simultaneously.

- There is inadequate awareness and information regarding proper nutritional practices amongst the population, particularly regarding nutritional care of infants, children, adolescents, and pregnant women. Yet, as stated above, programmes for nutrition education and behavioural change, particularly among the vulnerable sections of the community that suffer most from under-nutrition, were never conceptualized and initiated.

- Crucial prescriptions of the National Nutrition Policy, 1993, that could have had positive and sustainable impact on the nutritional status of the general public were not translated into National Programmes, viz., popularization of low cost nutritious foods, reaching the adolescent girl, fortification of essential foods and control of micronutrient deficiencies.

- India has no comprehensive National Program for the eradication of malnutrition. In general perception, the ICDS originally designed with a mandate for providing, inter alia, some nutritional services for children below six and pregnant and nursing mothers, is mistakenly seen as a programme to address malnutrition in India.

In India's complex, contemporary socioeconomic transition, manifested diversely and unevenly in different parts of the country, the gap in addressing under-nutrition lies not in lack of a Policy, but in the intent of translating its provisions into programmes backed by budgets. Ideally, the essential interventions of the NNP should have been woven into a national programme to combat under-nutrition long ago, with a definite implementation template of workable 
interventions on the ground. But the political will, or official initiative and skill to make that happen appear to have been absent.

Though some interventions included in the NNP do form core components of national programmes, such as, immunization, Vitamin A and Iron and Folic Acid, (IFA) administration, and national programmes for sanitation and safe drinking water were also initiated, there is no system in place to ensure that these critical inter-sectoral interventions operate simultaneously with full coverage of target groups.

Further, real-time monitoring systems, concurrent monitoring and evaluation, to ensure complete target group coverage by inter-sectoral interventions, and measure impact do not form part of the ICDS, or national health, water or sanitation programmes.

Without a national strategy and programme to combat under-nutrition, additional interventions, such as proposed in the Multi-Sectoral Programme to address the Maternal and Child Malnutrition in selected 200 high burden districts, or of the Sabla scheme, have over the last two decades been loaded on in an ad hoc manner to the anganwadi, which has neither trained manpower, nor the capacity or resources to implement them effectively. Hence, gaps, both structural and systemic, show up conspicuously in the disconnect between the causes of malnutrition in India and the interventions within existing programmes.

Even though the National Nutrition Policy has comprehensively covered the structural causes of under-nutrition and micronutrient deficiency in India, and made recommendations to address them, several critical recommendations remain unattended. For example, the most critical life-cycle and inter-sectoral interventions have not been structured into a single integrated template for implementation. There is very little advocacy or IEC for dissemination of child/ adolescent girl/maternal care or nutrition information for the community at grass roots to overcome the nutrition information gap. The protein-caloriemicronutrient deficit, (the most proximate cause of under nutrition), prevalent among diverse age groups among at least $50 \%$ of the population, remains unaddressed, even though confirmed by successive NNMB Repeat Surveys, including the latest in NNMB Technical Report Number, 2012.
What emerges is a visible asymmetry between structural causes of India's under-nutrition well stated in the NNP, and the ongoing programmes and interventions, the sum total of which do not address even a majority of them.

Even within on going, nutrition-related programmes and interventions, there are conspicuous systemic gaps at the cutting edge, community level, where the real interventions against under-nutrition must happen. Important systemic gaps lie in the provisioning for anganwadi infrastructure and manpower, providing a rationalized and practical charter of responsibilities to the anganwadi worker, establishing real-time monitoring mechanisms and accountability systems, creating systems for ensuring complete coverage of target groups, for inter-sectoral mechanisms at village level to engineer 'convergence', and for effective behaviour change strategies at the grassroots.

The minimum, basic inter-sectoral convergence for combating under-nutrition requires that every targeted family must simultaneously receive the following benefits - calorie-protein micronutrient supplementation to bridge the dietary deficit; complete immunization of children; IFA for addressing anaemia among children, women, and adolescent girls; safe drinking water; and hygienic sanitation. Four of these interventions already form part of national programmes. Unfortunately, there is no village functionary in the present implementation system, who is tasked with the responsibility of ensuring that the targeted households receive this complete package simultaneously, which alone can create positive transformational impact on reducing under-nutrition. Consequently, we have no data at the national, state or district level regarding the same; and inter-sectoral programmes instead of operating simultaneously, remain scattered.

Social Sector policies and programmes in India generally result from Constitutional commitments or commitments at international bodies, or through sustained internal demand or activism. Political governance in States is either demand driven or election driven. Popular demand for addressing malnutrition from the afflicted is absent, as the community lacks information and awareness regarding their own affliction or its causes. And absence of a national programme further inhibits 
community knowledge about undernutrition, which could have created demand. Clearly, a chicken and egg situation. Experience shows that public awareness and information dissemination on social and development issues is largely generated through the medium of strong national programmes, that themselves become the strongest advocacy tools taking the messages down to the grassroots, for example, the health, education and women's empowerment programmes. Information and awareness regarding malnutrition has no such medium. Hence, the vacuum in information at grassroots within families, community organizations, Panchayat Raj Institutions (PRIs) and field staff of Non Government Organisations (NGOs) and Government, regarding critical issues like preventing child under-nutrition, proper maternal nutritional care to ensure adequate pregnancy weight gain and prevent low birth-weight babies, (first casualties to neo-natal mortality), and nutritional care of adolescent girls, (the most under-nourished in the world), who are future mothers.

This lack of information and awareness is a major cause for the absence of capacity creation at all levels and stages of the participation/implementation process, and more importantly, it leads to absence of demand for nutritional services from the afflicted population, simply because they have no knowledge or awareness regarding their affliction. All these factors put together perhaps explain why there are hardly any think tanks, research or capacity building institutions at State or District Levels; no journals or information in local languages to inform rural populations, NGOs or local institutions about the subject, not even vernacular equivalents for terms like 'body mass index' or ‘chronic energy deficiency'.

The above factors cascade into the absence of an enabling environment for a united and vocal nutrition lobby with strong leadership to influence government, as exists in other sectors. There is negligible presence of Public Health/Nutrition curricula in research and medical institutions in State capitals and none at all in District/Block institutions, where the action really lies. Besides, the nutrition lobby is disunited, often deflecting attention from the urgency of addressing under-nutrition holistically, by generating adversarial debate on issues like food fortification, and low cost complementary food, not sparing even double fortified salt, or the Vitamin A prophylaxis programme. A strong, united nutrition lobby, providing innovation and working models could have acquired greater clout to prevail upon government to announce a national programme to address malnutrition, so urgently required in the country.

There has also been sustained prejudice against private sector cooperation in India's strategy to combat undernutrition or engage with them. The Government must motivate the private sector to take some measure of responsibility for making available appropriate low-cost energy foods for poor, undernourished and anaemic children, women, adolescent girls and boys, the sick, aged and infirm, in rural and urban markets. The numbers are large enough to support a viable business proposition, and this is the only sustainable solution for enabling the undernourished percentage of the population to bridge their macro and micro nutritional deficit for the present generation. There is a huge market vacuum in this respect, unfortunately filled up by forcefully advertised low-cost junk foods and tobacco products, which are consumed by the poor without any nutritional benefit. The presence of high cost energy foods for women, children and the general population, mostly marketed by global companies, is expanding in the market, and are consumed by middle class and higher income families. Why deny similar, more affordable products to the poor, who are most in need of them? (Rao V S, 2016).

\section{What Needs to be Done?}

To conclude, the problem of under-nutrition in India stems from lack of serious implementation of its National Nutrition Policy, 1993, which contains most of the prescriptions of the Five Year Plans. This in a situation of lack of demand, requires strong political will to implement it.

The silent under-nutrition crisis in India is one of alarm, particularly regarding children and adolescents, the potential work force of the country, who constitute $40 \%$ of the population, and Government response is urgently required. The NNP must be revisited and updated, and should address the problem holistically with reference to the latest demographic and epidemiological data, as reflected in the NNMB Reports covering all age groups of the population. 
Nutrition data of the 1970s and 80s, the ICDS era, related mostly to women and children. This is perhaps the reason why India's pandemic undernutrition, even today, is persistently viewed as a women and children's issue by government, NGOs, researchers, and academia. Undoubtedly, women and children are the worst sufferers, and hapless carriers of undernutrition, and require highest priority in a national programme. But additionally, the under-weight and stunting data of school going children above six years, of adolescent girls and boys, Chronic Energy Deficiency and micronutrient deficiency rates among adult men and women, is equally alarming and justifies that the problem of malnutrition be treated as a serious population issue. Inflation and price rise of food items have reduced food intake among the poor, further deteriorating their nutritional status. Direct evidence for this is forthcoming in the Karnataka Nutrition Mission Pilot Projects' data, confirmed by the NSSO $68^{\text {th }}$ Round, "Nutritional Intake in India" (2011-12) and NNMB Technical Report Number 26 (NNMB $3^{\text {rd }}$ Repeat Survey, 2011-12).

What India urgently needs is the political will to address under-nutrition through a national programme based on the NNP, backed by effective programmes and adequate financial allocations that address the structural and systemic causes, with monitorable targets, real-time monitoring and evaluation mechanisms, and accountability systems.

The good news was that the Finance Minister announced in his Budget speech on July 10, 2014, that "A national programme in Mission Mode is urgently required to halt the deteriorating malnutrition situation in India, as present interventions are not adequate. A comprehensive strategy including detailed methodology, costing, time lines and monitorable targets will be put in place within six months" (Budget Speech 2014).

The bad news is that the National Programme in Mission Mode to address malnutrition has not yet been formulated, even as in May 2016, as I write this. The Ministry of Women and Child Development has been grappling with the National Nutrition Mission for the past two years, but has not yet been able to produce a blueprint, or conceptualize a strategy to address the inter-sectoral and the population dimension of malnutrition. Strangely, there appears to be no public debate on the issue, and no questions have been raised in the public domain as to why this has not happened.

A national programme to combat undernutrition and micronutrient deficiency is perfectly doable, and should be based on the following principles:

- Bridging the protein-calorie-micronutrient deficit, which affects at least $50 \%$ of the population, by supplementation, either through government programmes or the market.

- Covering the entire life cycle of women and children so as to break the inter-generational cycle of malnutrition within the shortest possible time.

- Converging the multi-sectoral interventions at family and community levels to simultaneously address all or majority of direct and indirect causes of malnutrition simultaneously, many of which exist in ongoing programmes. Interventions include Direct Interventions, based on adequate food and micro-nutrients, immunization, Vitamin $A$ and IFA supplementation, use of iodized or double fortified salt, and Indirect Interventions, addressing issues of health, education, water, sanitation and sociocultural factors, like female literacy, late marriage, feeding children of both sexes equally, that are critical to eradicate malnutrition on a long term, sustainable basis.

- Initiating a sustained general public awareness campaign, through the multi-media and interpersonal communication mode to reach the general public, especially at the grass-root level, regarding proper nutritional practices in the family, and proper child, adolescent and maternal nutritional care.

- Establishing effective monitoring mechanisms and accountability through intensive and realtime monitoring of nutritional indicators (Karnataka Comprehensive Nutrition Mission, 2012 and Rao V S, 2008).

Lastly, we must note that drafting and implementing the National Nutrition Programme would require inter-sectoral coordination between major Ministries, most importantly, Ministries of Women \& Child Development, Health \& Family Welfare, Food, Agriculture, Rural Development, Drinking Water \& Sanitation, and Human Resource 
Development, and with State Governments. Can the Ministry of Women and Chid Development or any other single Ministry in the Government of India effectively steer such mega coordination between these major Ministries, which already have very substantive primary mandates of their own?

Experience of the last six decades starting from the First Five Year Plan, has established that the Government has not been able to come to grips with implementation of most of the multi-sectoral Plan prescriptions on nutrition, through a single Ministry. The Food and Nutrition Board (FNB) was established in the Department of Food, Ministry of Agriculture in 1964, with the objective of addressing the population dimension of nutrition, namely, diversifying Indian diet for improving the nutritional status of the people, development and popularization of subsidiary and protective foods, nutrition education, extension and food management, conservation and efficient utilization of food resources, and food preservation and processing. The FNB was transferred to the Department of Women and Child Development in 1993 in pursuance of the National Nutrition Policy. Thereafter, it has been completely eclipsed by the

\section{References}

Budget 2014-2015 Speech of Arun Jaitley, Minister of Finance (2014) http://indiabudget.nic.in/ub2014-15/bs/bs.pdf

Dharampal, Collected Writings, Volume III, The Beautiful Tree: Indigenous Indian Education in the Eighteenth Century (1983) http://www.arvindguptatoys.com/arvindgupta/ beautifultree.pdf

First Five Year Plan (1951-56), Chapter 32: Health http:// planningcommission.nic.in/plans/planrel/fiveyr/ welcome.html

Second Five Year Plan (1956-61), Chapter 25: Health http:// planningcommission.nic.in/plans/planrel/fiveyr/ welcome.html

Third Five Year Plan (1961-66), Chapter 32: Health and Family Planning http://planningcommission.nic.in/plans/planrel/ fiveyr/welcome.html

Fourth Five Year Plan (1969-74), Chapter 10: Food and Nutrition http://planningcommission.nic.in/plans/planrel/fiveyr/ welcome.html

Fifth Five Year Plan (1974-79) http://planningcommission.nic.in/ plans/planrel/fiveyr/welcome.html
ICDS, and has become an appendage to it, completely losing its population dimension described in the objectives stated above. Today, these objectives do not holistically form the mandate of any Ministry or Department of the Government of India. This is one of the major reasons why undernutrition and micronutrient deficiency in India is not reducing faster.

Clearly, no single Ministry can handle this extremely multi-sectoral subject. The national intersectoral programme to combat under-nutrition announced in the Budget speech, 2012, requires a Mission Mode, under a strong overarching, intersectoral authority. The highest inter-sectoral institution in the country, with a mandate for providing strategy and blueprints for addressing critical socio-economic and development issues, is now the Niti Aayog.

The Niti Aayog must take charge of this longorphaned subject, and constitute a High Power Committee headed by an eminent Social Scientist to revise the National Nutrition Policy, 1993 and prepare the blueprint for the National Nutrition Mission within a given time frame. And, those of us who are committed to this cause must work towards this.

Sixth Five Year Plan (1980-85) Chapter 22: Health, Family Planning and Nutrition http://planningcommission.nic.in/plans/ planrel/fiveyr/welcome.html

Tenth Five Year Plan (2002-07) Chapter 3.3: Food and Nutrition Security http://planningcommission.nic.in/plans/planrel/ fiveyr/index 1.html

NNMB First Repeat Survey (Rural) (1988-99) http:// nnmbindia.org/NNMB-PDF\%20FILES/Report_OF_1st\% 20Repeat_Surveys88-90.pdf

NNMB-Report of the Second Repeat Survey (Rural) (1996-97) http://nnmbindia.org/NNMB-PDF\%20FILES/ Report_OF_2nd\%20Repeat_Survey-96-97.pdf

NNMB-Report of the Third Survey: "Diet and Nutritional Status of Rural Population. Prevalence of Hypertension and Diabetes among Adults and Infants and Young Child Feeding Practices”(2011-12) http://nnmbindia.org/ 1_NNMB_Third_Repeat_Rural_Survey__Technicl_Report_26. pdf

NSSO $68^{\text {th }}$ Round-"Nutritional Intake in India” (2011-12) http:/ /mospi.nic.in/mospi_new/upload/nss_report_560_ 19dec14.pdf 
National Commission on Population, Ministry of Health and Family Welfare, Government of India http://populationcommission.nic.in/Publication/19_4.aspx

National Family Health Survey 4 (NFHS-4) (2015-16): Factsheets http://rchiips.org/nfhs/factsheet_nfhs-4.shtml

Ram P (2014) Life in India https://books.google.co.in/books?id= OjT4BQAAQBAJ\&pg=PA318\&lpg=PA318\&dq= nutrition+of+the+people+of+india+in+mughal+ times \& source=bl\&ots=rAZ4rROPEZ\&sig= K7IcEWYCKO_T2QNOMK CzOvmdUmc\&hl=en\&sa= X\&ved=0ahUKEwjt6fenbbMAhUnMaYKHXkw CY84ChDoAQhMMAg\#v=onepage $\& \mathrm{q}=$ nutrition $\%$ 20 of $\% 20$ the $\% 20$ people $\% 20$ of $\% 20$ india $\% 20$ in $\%$ 20mughal\%20times\&f=false

Rao V S, Malnutrition, an Emergency, What it Costs the Nation, (2008) CAPART
Rao V S, Undernutrition and Public Policy in India (2016) Routledge, Chapter 8, Undernutrition in India: A Case of Public Policy Inertia

Report of the Health Survey and Development Committee (1946) http://www.nhp.gov.in/sites/default/files/pdf/Bhore_ Committee_Report_VOL-1.pdf

Shah D (2012) The beautiful tree, a historical perspective of Dharmpal in two parts http://bharatkalyan97.blogspot.in/ 2012/12/the-beautiful-tree-historical.html

Strategy Paper, Karnataka Comprehensive Nutrition Mission (2012) http://www.karnutmission.org/Strategy\%20Paper\% 20KARNATAKA \% 20COMPREHENSIVE\% 20NUTRITION\%20MISSION.pdf

Spears D (2013) How Much International Variation in Child Height Can Sanitation Explain? http://sanitationdrive 2015.org/wp-content/uploads/2013/09/sanitationheight.pdf. 